\title{
Comparisons of endocrinology and behavioural events during the periovulatory period in Meishan and Large-White hybrid gilts
}

\author{
M. G. Hunter ${ }^{1}$, C. Biggs ${ }^{1}$, G. R. Foxcroft ${ }^{2}$, A. S. McNeilly ${ }^{3}$ and \\ J. E. Tilton ${ }^{4}$ \\ ${ }^{1}$ AFRC Research Group on Hormones and Farm Animal Reproduction, Faculty of Agricultural and \\ Food Sciences, University of Nottingham, Sutton Bonington, Leics., LE12 5RD, UK; ${ }^{2}$ Department of \\ Animal Science, University of Alberta, Edmonton, Canada T6G 2P5; ${ }^{3} M R C$ Reproductive Biology \\ Unit, Centre for Reproductive Biology, 37 Chalmers St, Edinburgh, EH3 9EW, UK; and ${ }^{4}$ Department \\ of Animal and Range Sciences, North Dakota State University, Fargo, ND, USA
}

\begin{abstract}
Attainment of puberty, cycle lengths, ovulation rate and endocrinology during the periovulatory period were studied in Meishan (MS) and European Large-White hybrid (LW) gilts. The mean age at onset of puberty of 115 days in MS $(n=20)$ gilts was younger $(P<0.001)$ than the 235 days in $\operatorname{LW}(n=23)$. In the MS population studied, ovulation rate was not different $(P>0.1)$ during the third and fourth oestrous cycles, nor were there differences $(P>0.1)$ in the mean cycle length over the first three cycles. Overall changes in plasma luteinizing hormone (LH), follicle-stimulating hormone (FSH) and oestradiol did not differ significantly $(P>0.1)$ between the breeds (MS, $n=6 ; \mathrm{LW}, n=5)$ during the periovulatory period, but plasma inhibin concentrations were significantly $(P<0.05)$ higher in the MS. The time intervals from the oestradiol peak concentration and the onset of the $\mathrm{LH}$ surge until the onset of behavioural oestrus were significantly different $(P<0.005)$ between the breeds, with oestrus occurring earlier in the MS. However, no difference $(P>0.1)$ was found between the groups when the intervals from the peak oestradiol concentration to the onset of the LH surge were compared. These results indicate differences between the breeds, particularly in terms of the age of attainment of puberty and the timing of the onset of behavioural oestrus relative to the oestradiol and LH surges.
\end{abstract}

\section{Introduction}

Chinese Meishan pigs are generally characterized by sexual precocity and enhanced prolificacy when compared with European breeds (Bazer et al., 1988). A major component of the prolificacy is increased prenatal survival (Bolet et al., 1986; Bazer et al., 1988; Bidanel et al., 1989). However, little is known about the endocrine mechanisms mediating such differences in reproductive performance. Preliminary studies by Ellendorff et al. (1988), with a population of Meishan (MS) gilts derived from an importation into France in 1979, indicated that not only did MS pigs display a longer duration of oestrous behaviour than their Large-White hybrid (LW) counterparts, but also that concentrations of $\mathrm{LH}$ during the preovulatory surge were higher in the MS. Other studies with pigs from the same population have also shown a longer period of behavioural oestrus in MS pigs when compared with European breeds, and a longer interval from the onset of behavioural oestrus to ovulation; cycle length was, however, shorter (Bazer et al., 1988). There are conflicting reports with regard to ovulation rate; a lower ovulation rate was reported in the MS than in the European breeds (Bazer ef al., 1988; Bolet et al., 1986), whereas others (Ashworth et al.,

Received 21 April 1992
1990, 1992; Haley and Lee, 1990) reported a higher ovulation rate in a population of MS gilts imported to the UK in 1987.

Several of these earlier comparisons appear to be confounded by comparing MS and other breeds of gilts at different physiological ages. The present study was carried out to compare age at puberty, cycle length and ovulation rate between MS and LW pigs that had experienced a similar number of oestrous cycles, and to determine oestradiol, LH, FSH and inhibin secretion during the periovulatory phase in MS and LW pigs and relate these changes to the onset of behavioural oestrus.

\section{Materials and Methods}

\section{Animals}

Twenty prepubertal MS gilts and three MS boars were transported from the Edinburgh Station of the Institute of Animal Physiology and Genetics Research (IAPGR) at 7-8 weeks of age. These were from a population derived from the importation from China in 1987. Twenty-three prepubertal Landrace $\times$ (Landrace $\times$ Large White) gilts (LW) and three LW boars were transported locally from the University of Nottingham herd at the age of 20-24 weeks. On acquisition all 
gilts were checked daily for oestrous behaviour with mature vasectomized boars of the appropriate breed, and the day of onset of puberty and subsequent cycle lengths were recorded.

Ovulation rates were determined in MS $(n=13)$ and LW $(n=8)$ during the luteal phase of the third cycle by laparoscopy or laparotomy, and at the end of the fourth cycle by counting the number of corpora albicantia present when the ovaries (MS, $n=19$ gilts; LW, $n=19$ gilts) were recovered on predicted day 20 of the cycle for the follicular study described by Biggs et al. (1990, 1993).

\section{Cannulation and blood sampling}

From the original pool of animals, five LW and four MS gilts were surgically fitted with indwelling jugular cannulae under general anaesthesia three days before the predicted onset of fourth oestrus; owing to the availability of animals, two additional MS gilts were cannulated before the third and sixth oestrus.

Blood samples were withdrawn at I h $(3 \mathrm{ml}$ for determination of LH, FSH and inhibin) and $8 \mathrm{~h}(5 \mathrm{ml}$ for determination of oestradiol in addition to the above) intervals over a 4 day period, with a $3 \mathrm{~h}$ frequent sampling period on day 2 of the sampling regimen when the samples $(3 \mathrm{ml}$ for $\mathrm{LH}$ and $\mathrm{FSH}$ ) were taken at intervals of $10 \mathrm{~min}$. The blood was collected into heparinized tubes and centrifuged at $1500 \mathrm{~g}$ for $20 \mathrm{~min}$. Plasma was stored at $-20^{\circ} \mathrm{C}$ until analysed for $\mathrm{LH}, \mathrm{FSH}$, inhibin and oestradiol as described below. After the withdrawal of each blood sample, cannulae were flushed with $1 \mathrm{ml}$ of sterile, heparinized (10 iu $\mathrm{ml}^{-1}$ ) saline.

During the sampling period, gilts were checked hourly for onset of behavioural oestrus by testing for a lordosis response to back pressure.

\section{Hormone radioimmunoassays}

Plasma LH concentrations were determined in duplicate $200 \mu \mathrm{l}$ samples by a homologous double-antibody radioimmunoassay using a goat antiserum (GRF-G81-1), described by Cosgrove et al. (1991). The purified LH preparation IVO $(0.77 \times \mathrm{NIH}$ ovine $\mathrm{LH}-\mathrm{S1})$ was used as a reference standard. Intra- and interassay coefficients of variation were 6.2 and $9.3 \%$, respectively, and the limit of sensitivity of the assay was 17.0 pg per tube.

Plasma FSH concentrations were determined in duplicate $100 \mu \mathrm{l}$ samples by a homologous double-antibody radioimmunoassay using a rabbit antiserum (USDA-398-04P, USDA Animal Hormone Program, Reproduction Laboratory, Beltsville, USA), described by Cosgrove et al. (1991). Purified pig FSH was used as a reference standard (USDA porcine FSH-BI, $0.98 \times \mathrm{NIH}$ ovine FSH-SI). Intra- and interassay coefficients of variation were 7.6 and $18.7 \%$, respectively, and the limit of sensitivity was $0.55 \mathrm{ng}$ per tube.

Plasma oestradiol concentrations were determined in duplicate $200 \mu \mathrm{l}$ samples by a radioimmunoassay according to the extraction method of Webb et al. (1985) using the same antibody (raised in rabbits against oestradiol-11 $\beta$-succinyl-bovine serum albumin) and conjugated hormone for iodination (oestradiol-11 $\alpha$ succinyl-tyrosinemethylester). The assay procedure was validated for porcine plasma by the extraction of known amounts of oestradiol from charcoal stripped pig plasma and there was no effect when different sample volumes were assessed. The slope of the extracted samples was parallel to the standard curve with a correlation $r=0.92$. The range of the standard curve was $0.125-32 \mathrm{pg}$ per tube and the limit of sensitivity was $0.32 \mathrm{pg}$ per tube. Intra- and interassay coefficients of variation were 11.1 and $19.2 \%$, respectively.

Plasma inhibin concentrations were determined in duplicate $50 \mu \mathrm{l}$ samples by a radioimmunoassay using a rabbit antiserum (R-150), described by McNeilly et al. (1989), which was directed against a synthetic fragment of the $1-26$ amino acid sequence of the amino terminus of the $\alpha$ chain of $32 \mathrm{kDa}$ porcine inhibin (the free $\alpha$-subunit). This inhibin peptide fragment was also used as the standard. The intra- and interassay coefficients of variation were 9.4 and $12.6 \%$, respectively, and the limit of sensitivity was 5 pg per tube.

\section{Statistical analyses}

The following analyses were performed using the GENSTAT statistical package (GENSTAT 5 Committee, 1989) Student's t test was used to compare age at onset of puberty, initial cycle lengths and ovulation rate between the breeds. Endocrine profiles were standardized to the time of onset of the LH surge. The duration of the LH surge, FSH surge and the interval from the onset of behavioural oestrus to the onset of the LH surge and peak oestradiol concentration were compared using Student's $t$ test. The frequent sampling period was used to establish basal $\mathrm{LH}$ and FSH concentrations (except in the case of one LW whose LH surge occurred during the frequent sampling period and thus basal concentrations were established over ten of the previous hourly samples) and the surge onset in each case was defined as a sustained increase of two standard deviations above the mean basal values. The duration was defined as the interval over which the surge was sustained two standard deviations above the basal mean.

The following endocrine characteristics were compared between the breeds by an analysis of variance and the pooled variance estimate used to calculate the standard error of the difference (SED), although for clarity, individual standard errors of the mean (SEM) are shown. Surge release of LH and FSH were compared by an analysis of the area under the curve. Peak surge values for $\mathrm{LH}, \mathrm{FSH}$ and oestradiol were defined as the highest concentration ( + one sample either side of this value) observed for each hormone. Basal concentrations of LH and FSH were analysed using mean concentrations over the $36 \mathrm{~h}$ before onset of surge. Inhibin concentrations were analysed using mean concentrations throughout the periovulatory period from $36 \mathrm{~h}$ before to $34 \mathrm{~h}$ after onset of $\mathrm{LH}$ surge. The data were also split into pre- and post-LH surge onset and compared between the breeds and within a breed for both periods.

\section{Results}

\section{Onset of puberty, cycle length and ovulation rate}

First oestrus (puberty) was observed at an earlier age $(P<0.001)$ in MS than in LW gilts (Table 1 ), but oestrous cycle 
Table 1. Mean and SD of the age at onset of puberty (days) and duration of the first three oestrous cycles (days) in Meishan (MS) and Large-White hybrid (LW) gilts

\begin{tabular}{lccccc}
\hline & \multicolumn{3}{c}{ MS } & & \multicolumn{2}{c}{ LW } \\
\cline { 2 - 3 } \cline { 5 - 6 } & $\begin{array}{c}\text { Age at onset } \\
\text { of puberty } \\
\text { (days) }\end{array}$ & $\begin{array}{c}\text { Cycle } \\
\text { length } \\
\text { (days) }\end{array}$ & & $\begin{array}{c}\text { Age at onset } \\
\text { of puberty } \\
\text { (days) }\end{array}$ & $\begin{array}{c}\text { Cycle } \\
\text { length } \\
\text { (days) }\end{array}$ \\
\hline Mean & 115 & 20.0 & & 235 & 20.4 \\
SD & 20.1 & 1.2 & & 21.7 & 1.4 \\
$n$ & 20 & 59 & & 23 & 64 \\
\hline
\end{tabular}

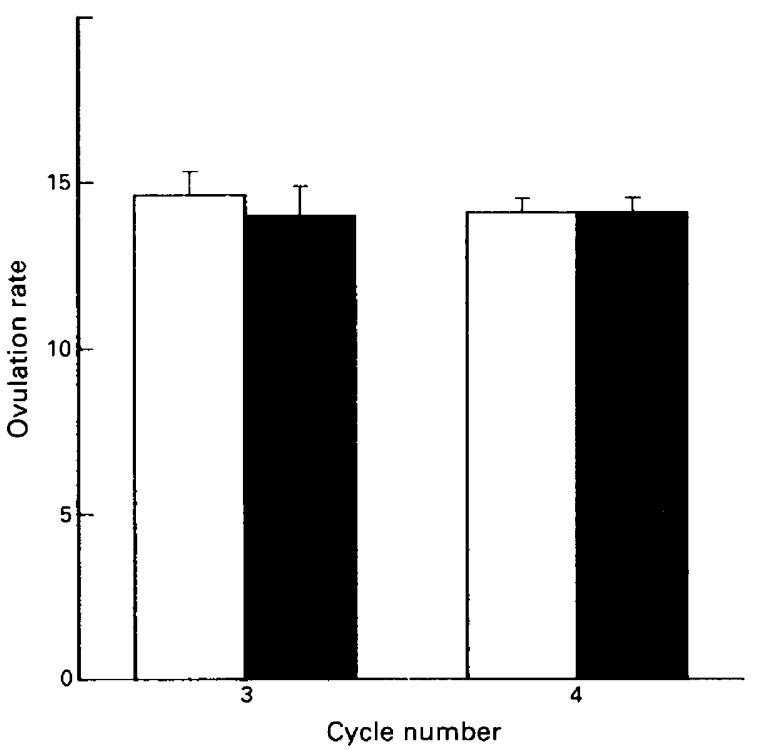

Fig. 1. Mean and SD of ovulation rate at third and fourth oestrous cycles for Meishan ( $\square)(n=13$ and 19 for third and fourth cycle, respectively) and Large-White hybrid ( $(n=8$ and 19 for third and fourth cycles, respectively) gilts.

length was not different between breeds during the first three cycles $(P>0.1)$. Ovulation rates during the third and fourth oestrous periods were similar $(P>0.1)$ : 14.9 versus 14.0 in MS and LW, respectively, during the third and I4.I in both breeds during the fourth cycles (Fig. 1).

\section{Time of onset of behavioural oestrus}

MS gilts demonstrated oestrus earlier $(P<0.005)$ than their $\mathrm{LW}$ counterparts (Fig. 2). The mean intervals between the onset of the LH surge to the onset of oestrus were $0.5 \pm 12.4 \mathrm{~h}$ (with a range of -15 to $+14 \mathrm{~h}$ ) for MS and $32.4 \pm 10.6 \mathrm{~h}$ (with a range of +14 to $+40 \mathrm{~h}$ ) for LW. A difference $(P<0.005)$ between the breeds was also noted when the interval from the peak concentration of oestradiol in plasma until the time of onset of behavioural oestrus was compared $(4.2 \pm 15.0$ versus
$33.6 \pm 7.6 \mathrm{~h}$ for MS and LW, respectively). However, no difference $(P>0.5)$ was found in the interval from the peak concentration of oestradiol until the mean onset of the $\mathrm{LH}$ surge $(3.7 \pm 5.7$ versus $1.2 \pm 8.0 \mathrm{~h}$ for the MS and LW, respectively).

\section{Number of animals sampled}

The blood sampling regimen was defined as a four day period designed to commence two days before the onset of oestrus. However, owing to the variability in the precise time of onset of oestrus, the number of animals represented in each part of this sampling window did not remain constant. From $36 \mathrm{~h}$ before the onset of the $\mathrm{LH}$ surge until $34 \mathrm{~h}$ after the onset of the surge, numbers of animals were six for MS and five for LW; from $35-40 \mathrm{~h}$ after $\mathrm{LH}$ surge onset, the numbers of animals declined to two MS and four LW gilts.

\section{Periovulatory endocrine changes}

There were no significant differences $(P>0.1)$ between the breeds in terms of mean basal LH and FSH concentrations $(0.25$ versus $0.23 \mathrm{ng} \mathrm{ml}^{-1}, \mathrm{SED}=0.28$ for $\mathrm{LH}$, and 7.33 versus $4.87 \mathrm{ng} \mathrm{ml}^{-1}, \mathrm{SED}=3.56$ for FSH in MS and LW, respectively), or peak $\mathrm{LH}$ (1.44 versus $1.21 \mathrm{ng} \mathrm{ml}^{-1}$, for MS and $\mathrm{LW}$, respectively; SED $=0.21)$ and $\mathrm{FSH}\left(34.4\right.$ versus $28.5 \mathrm{ng} \mathrm{ml}^{-1}$ for MS and LW, respectively; SED = 7.9) surge concentrations or the area under the curve for LH and FSH (Fig. 2). The duration of the $\mathrm{LH}$ surge $(31.6 \pm 8.6$ versus $35.0 \pm 7.8 \mathrm{~h}$ for MS and LW, respectively) and the FSH surge (18.8 \pm 2.8 versus $22.3 \pm 3.95 \mathrm{~h}$ for MS and $\mathrm{LW}$, respectively) were also similar between breeds $(P>0.1)$. Both breeds exhibited a second rise in FSH concentration after the first peak, but because of the low number of animals sampled during this period, no analysis was performed.

Oestradiol peak values ( 41.8 versus $32.1 \mathrm{pg} \mathrm{ml}^{-1}$ for $\mathrm{MS}$ and $L W$, respectively; SED $=3.7)$ and area under the curve $(27.8$ versus $22.0 \mathrm{pg} \mathrm{ml}^{-1} \mathrm{~h}^{-1}$ for MS and LW, respectively; SED = 4.7) were not significantly different $(P>0.1)$ between the breeds.

The concentration of inhibin was significantly $(P<0.05)$ higher in the MS than in the LW when analysed over the entire periovulatory period $\left(0.57\right.$ versus $0.47 \mathrm{ng} \mathrm{ml}^{-1}$ for $M S$ and $L W$, respectively; SED $=0.04$ ). Inhibin concentration was significantly higher $(P<0.05)$ in the MS after the LH surge, but before the onset of the surge this was only a trend $(P=0.09)$. There was no difference $(P>0.1)$ in the circulating inhibin concentration for either MS or LW when values before and after the onset of the LH surge were compared within a breed.

\section{Discussion}

The observation that MS gilts achieve puberty at a significantly earlier age than their LW counterparts confirms previous observations on the population of MS gilts imported into France in 1979 (Bolet et al., 1986; Bazer et al., 1988). The age at onset of pubertal oestrus in the MS of 115 days in the present study was similar to the mean of 114.7 days reported by Haley et al. 


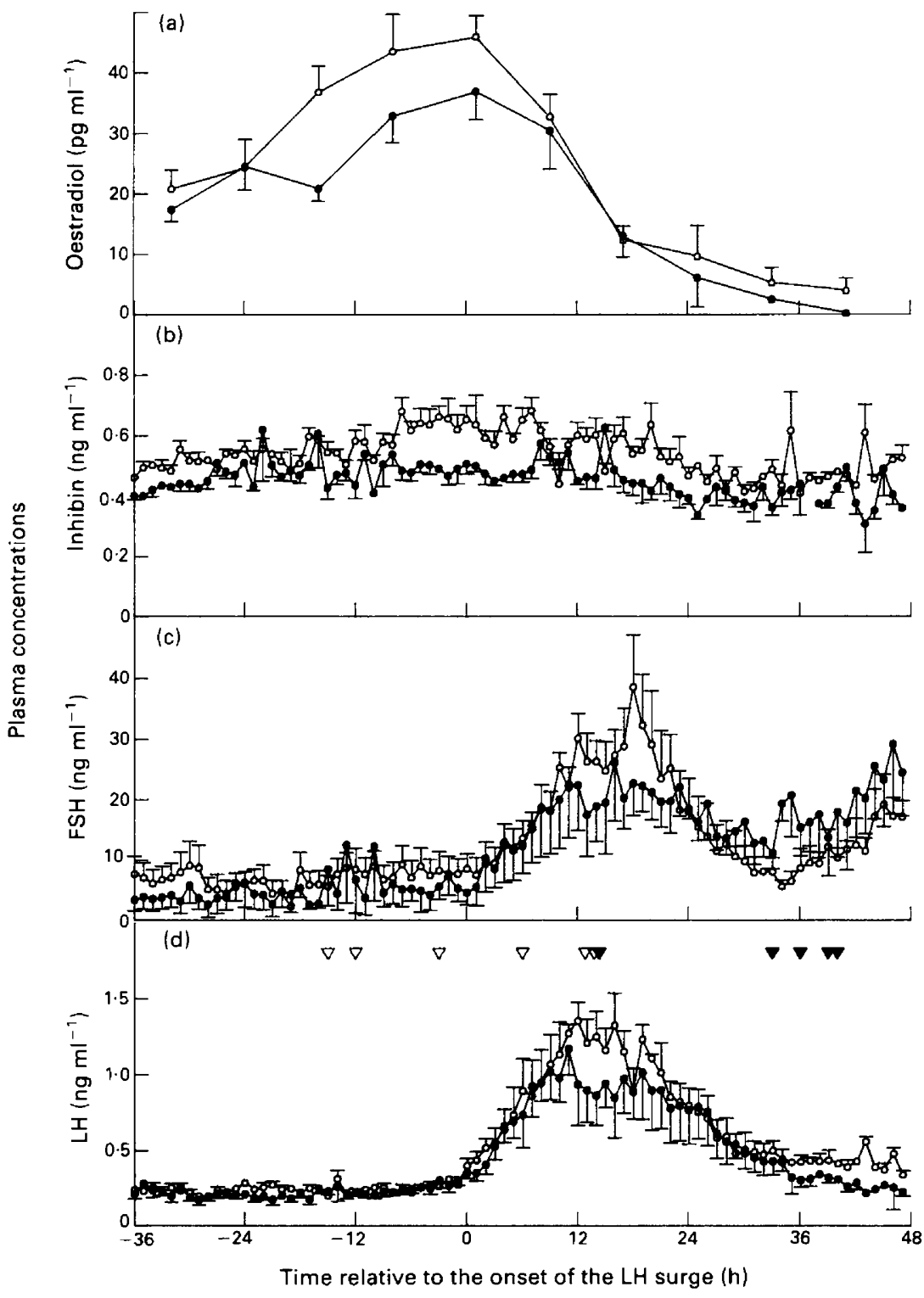

Fig. 2. Endocrine profiles showing the mean and SEM for (a) oestradiol, (b) inhibin, (c) FSH and (d) LH synchronized at about the onset of the LH surge for Meishan (MS) $(0 ; n=6)$ and Large-White hybrid (LW) $(0 ; n=5)$ gilts. The onset of behavioural oestrus is indicated for each gilt, $\mathrm{MS}(\nabla)$ and $\mathrm{LW}(\boldsymbol{\nabla})$.

(1990) in the population of MS imported into the UK in 1987. Although the MS females studied in France have been reported to have shorter oestrous cycles (Bazer et al., 1988), this was not supported by our present observations, nor did we detect any difference in length of the first, second or third oestrous cycle. The reason for these discrepancies is unclear, although the MS cycle was reported by others to be shorter by only one day and a larger number of animals and a more frequent oestrous detection regimen may be required to detect these differences, if they exist.

The comparison of ovulation rate at the third and fourth cycle indicated no differences between the breeds. There is some disagreement in the literature on ovulation rate; a lower ovulation rate was reported in the population of MS pigs imported into France than in European breeds (Bolet et al., 1986; Bazer et al., 1988). In contrast, Haley and Lee (1990) and Ashworth et al. (1990) observed a higher ovulation rate in the population of MS pigs imported into the UK; they also suggested that the ovulation rate in the MS may be underestimated unless the corpora lutea were dissected from the ovary, since some corpora lutea are buried in the ovary, and not visible by superficial inspection. However, this does not account for the discrepancy in results from the gilts studied in the present experiment and those published by others investigating the British population of Meishans, as our estimates of ovulation rate at the fourth cycle were determined by dissection of the ovaries. We suggest 
that the results obtained in previous reports and in the different groups have been confounded by age, environmental factors, number of oestrous cycles experienced, parity and also the European breed used for comparison. In our study, we compared the breeds at a similar oestrous cycle number, as did Bazer et al. (1988) and Bolet et al. (1986). Although Haley and Lee (1990) observed large numbers of Meishan pigs, many of these were sows that would have experienced several oestrous cycles prior to breeding and probably a greater number of cycles than the LW of similar parity with which they were compared. It is well known that cycle number and parity affect ovulation rate (Anderson, 1987). Similarly, many of the results reported by Ashworth et al. (1992) were obtained from sows, although they did report a higher ovulation rate in MS gilts that were investigated after second or third oestrus. More recent investigations of our population of MS gilts at the seventh oestrous cycle have shown that these animals have a higher ovulation rate (17.4 $\pm 0.5, n=5$ ) than those examined at third or fourth cycle (L. S. Faillace, C. Biggs and M. G. Hunter, unpublished). It is suggested that a proportionately greater increase in ovulation rate occurs in MS after they have experienced pregnancy than with European breeds (R. K. Christenson, personal communication). The early onset of puberty in the MS can be achieved at a bodyweight as low as $15.8 \mathrm{~kg}$ (Faillace et al., 1991) and the production of a large litter at this body size might not be advantageous.

The duration of oestrus has been reported to be longer in MS than in LW pigs (Bolet et al., 1986; Bazer et al., 1988), and the mean time of ovulation after onset of oestrus was subsequently reported as approximately $44-49 \mathrm{~h}$ for $\mathrm{MS}$ and 33-38 h for LW females (Terqui et al., 1990; Faillace et al., 1991; Wilmut et al., 1992). However, the relationship between the onset of oestrus and the $\mathrm{LH}$ surge, and the $\mathrm{LH}$ surge and ovulation was not known. The present study provides evidence that the LH surge occurred later in the MS relative to the onset of behavioural oestrus than in LW pigs, and suggests that this accounts for the large difference in time of ovulation from oestrus onset. In the present study there was a large variation within the breeds for the interval between the onset of oestrus and the onset of the LH surge and variation in this interval has been reported by previous workers (Hughes and Varley, 1980; Tilton et al., 1982; Anderson, 1987). Subsequent work (Faillace et al., 1991) demonstrated that the interval from behavioural oestrus to ovulation is similar to that reported by Wilmut et al. (1992) and Terqui et al. (1990).

Since circulating oestradiol concentrations were not significantly different between the breeds, the MS appear to be more sensitive to oestradiol in terms of initiating a behavioural response, but not in terms of positive feedback, as the interval from peak oestradiol to the onset of the $\mathrm{LH}$ surge was similar in both breeds. A greater interval between the onset of oestrus and LH surge discharge has been reported in prolific breeds of sheep (Land et al., 1973) and it is possible that this has arisen from a difference in oestrogen secretion patterns or alternatively from a different sensitivity to oestrogen feedback control of oestrous behaviour.

In contrast to the initial work by Ellendorff et al. (1988), there were no significant differences in the gonadotrophin and oestradiol profiles between the two breeds; however, the mean concentration for each hormone was higher in the MS than in the $\mathrm{LW}$. The variation between the animals may have prevented us from establishing a significant difference between the breeds. There was no evidence of a fall in inhibin concentrations coincident with the FSH surge as observed by Mukai et al. (1989) and Hasegawa et al. (1988) in the cyclic gilt, but inhibin concentrations were significantly higher in the MS than in the LW during the periovulatory period. This was despite the fact that concentrations in follicular fluid from individual preovulatory follicles in animals at a similar reproductive age (Biggs et al., 1993) tended to be lower in the MS than in the LW. The higher concentration of inhibin in the plasma of the MS suggests that either the smaller nonovulatory follicular population was secreting inhibin in appreciable quantities, as in ewes (Campbell et al., 1991), or non-ovarian sources of inhibin (Knight, 1991) were making a significant contribution to circulating concentrations or both of these occurred. Although inhibin concentrations were raised in the MS, there was no apparent reduction in circulating FSH concentrations. It is possible that not all the inhibin measured in the plasma was bioactive, as the radioimmunoassay directed towards the amino terminus of the $32 \mathrm{kDa} \alpha$-subunit of inhibin will also measure any free $\alpha$-subunit in the plasma, which is thought to be biologically inactive. It is not known how abundant the free $\alpha$-subunit of inhibin is in pigs, but Hasegawa et al. (1988) demonstrated that their radioimmunoassay which is directed towards the amino terminus of the $32 \mathrm{kDa} \alpha$-subunit of porcine inhibin correlated well with the pattern of bioactive inhibin in porcine follicular fluid. Another conclusion could be that there was decreased sensitivity to feedback of inhibin on FSH secretion in MS gilts; this is supported by evidence that treatment with charcoal-stripped porcine follicular fluid was less effective in reducing FSH in castrate MS than in castrate LW gilts (Tilton et al., 1991). It is also interesting to note that there have been reports of a higher circulating concentration of inhibin in prolific breeds of sheep during the late follicular phase (Tsonis et al., 1988) and also of a lower follicular inhibin concentration in Booroola ewes (Cummins et al., 1983; Driancourt et al., 1991).

In conclusion, these studies have confirmed the earlier onset of puberty in the MS. The difference in timing of the onset of behavioural oestrus relative to the $\mathrm{LH}$ surge explains previous observations of a longer interval from oestrus to ovulation in the MS and suggests that this is a consequence of an earlier onset of behavioural oestrus in this breed. In the study reported here ovulation rate and the pattern of circulating $\mathrm{LH}, \mathrm{FSH}$ and oestradiol during the periovulatory period were similar between breeds. However, the inhibin concentration was higher in the MS and this requires further investigation.

We would like to thank the AFRC (UK) and the NSERC and APPDC (Canada) for financial support, and D. F. M. Van de Wiel, S. D. Glenn, D. G. Bolt and R. Webb for gifts of purified hormones and antisera. Thanks also to the members of JABU, L. Hill, W. Crowe and L. Wright for technical assistance. C. Biggs was in receipt of a MAFF Postgraduate Scholarship.

\section{References}

Anderson LL (1987) Reproductive Cycles-Pigs. In Reproduction in Farm Animals Ed ESE Hafez. Lea and Fabiger, Philadelphia 
Ashworth CJ, Haley CS, Aitken RP and Wilmut I (1990) Embryo survival and conceptus growth after reciprocal embryo transfer between Chinese Meishan and Landrace $\times$ Large White gilts Joumal of Reproduction and Fertility 90 595-603

Ashworth CJ, Haley CS and Wilmut I (1992) Effect of Regumate on ovulation rate, embryo survival and conceptus growth in Meishan and Landrace $X$ Large White gilts Theriogenology 37 433-443

Bazer FW, Thatcher WW, Martinat-Botte F and Terqui M (1988) Sexual maturation and morphological development of the reproductive tract in Large White and prolific Chinese Meishan pigs Journal of Reproduction and Fertility $83723-728$

Bidanel JP, Caritez JC and Legault C (1989) Estimation of crossbreeding parameters between Large White and Meishan porcine breeds. 1. Reproductive performance Genetics, Selection, Evolution 21 507-526

Biggs C, Hunter MG, Craigon J, Wilmut I, Tilton JE and Foxcroft GR (1990) A comparison of preovulatory follicles in Meishan and Large White pigs. In Symposium Sur Le Porc Chinois pp 41-42, Abstract Eds N Molenat and C Legault. INRA, Toulouse, France

Biggs C, Tilton JE, Craigon J, Foxcroft GR, Ashworth CJ and Hunter MG (1993) Comparison of follicular heterogeneity and ovarian characteristics in Meishan and Large-White hybrid pigs Journal of Reproduction and Fertility 97 263-269

Bolet G, Martinat-Botte F, Locatelli A, Gruand J, Terqui M and Berthelot F (1986) Components of prolificacy in hyperprolific Large White sows compared with the Meishan and Large White breeds Genetics, Selection, Evolution $18333-342$

Campbell BK, McNeilly AS, Mann GE and Baird DT (1991) The effect of stage of oestrus and follicular performance on ovarian inhibin production in sheep Biology of Reproduction 44 483-490

Cosgrove JR, Booth PJ and Foxcroft GR (1991) Opiodidergic control of gonadotrophin secretion in the prepubertal gilt during restricted feeding and realimentation journal of Reproduction and Fertility 91 277-284

Cummins LJ, O'Shea T, Bindon BM, Lee VWK and Findley JK (1983) Ovarian inhibin content and sensitivity to inhibin in Booroola and control Merino ewes Journal of Reproduction and Fertility 67 I-7

Driancourt MA, Fry RC, Campbell BK and McNeilly AS (1991) Granulosa cell content and production of steroids, inhibin and follicular peptides by large follicles from a range of prolific and non-prolific sheep breeds Journal of Reproduction and Fertility Supplement 43 230-231

Ellendorff F, Martinat-Botte F, Signoret J-P and Terqui M (1988) Duration of oestrus and preovulatory LH in the high fertility Meishan pig Proceedings of the 11th World Congress on Animal Reproduction \& A.I. (Dublin), 224

Faillace LS, Biggs C, Haley CS and Hunter MG (1991) Timing and reproductive characteristics in Chinese Meishan gilts Journal of Reproduction and Fertility Abstract Series 8 Abstract 83
Genstat 5 Committee (1989) Genstat 5 Reference Manual, Clarendon Press, Oxford, UK

Haley CS and Lee GS (1990) Genetic components of litter size in Meishan and Large White pigs and their crosses Proceedings of the 4th World Congress of Genetics Applied to Livestock Production Edinburgh, UK, XV 458-461

Haley CS, Ashworth CJ, Lee GS, Wilmut I, Aitken RP and Ritchie W (1990) British studies on the genetics of prolificacy in the Meishan pig. In Symposium sur le Porc Chinois pp 83-97 Eds N Molenat and C Legault. INRA, Toulouse, France

Hasegawa Y, Miyamoto K, Iwamara S and Igarashi M (1988) Changes in serum concentration of inhibin in cyclic pigs Journal of Endocrinology 118 211-219

Hughes PE and Varley MA (1980) Reproduction in the Pig Eds PE Hughes and MA Varley. Butterworths, London

Knight PG (1991) The identification and purification of inhibin and inhibinrelated proteins Journal of Reproduction and Fertility Supplement 43 111-123

Land RB, Pelletier J, Thimonier J and Mauléon P (1973) A quantitative study of genetic differences in the incidence of oestrus, ovulation and plasma $\mathrm{LH}$ concentration in the sheep Joumal of Endocrinology 58 305-317

McNeilly AS, Swanston IA, Crow W, Tsonis CG and Baird DT (1989) Changes in plasma concentrations of inhibin throughout the normal sheep oestrous cycle and after the infusion of FSH Journal of Endocrinology 120 295-305

Mukai S, Mori Y, Nagashima H, Hasegawa Y. and Hoshino K (1989) Changes in plasma gonadotrophins, ovarian steroids and inhibin concentrations in gilts following progesterone treatment with implantable osmotic pumps Animal Reproduction Science 20 287-297

Terqui M, Bazer FW and Martinat-Botte F (1990) Mechanisms involved in the high prolificacy of the Meishan breed. In Symposium Sur Le Porc Chinois pp 17-32 Eds N Molenat and C Legault. INRA, Toulouse, France

Tilton JE, Foxcroft GR, Ziecik AJ, Coombs SL and Williams GL (1982) Time of the preovulatory LH surge in the gilt and sow relative to the onset of behavioral oestrus Theriogenology 18 227-236

Tilton JE, Biggs C, Hunter MG, Haley CS and Foxcroft GR (1991) Gonadotropin secretion after EB and pFF challenges in castrate Chinese MS and LW gilts Biology of Reproduction 44 Supplement 1145 (Abstract)

Tsonis CG, Baird DT, Campbell BK, Downing JA and Scaramuzzi RJ (1988) Secretion of bioactive inhibin by the ovary of the Booroola Merino ewe with or without a copy of the fecundity $(\mathrm{F})$ gene Journal of Endocrinology 119 R5-R8

Webb R, Baxter G, McBride D, Nordbloom GP and Shaw MDK (1985) The measurement of testosterone and oestradiol $17-\beta$ using iodinated tracer and incorporating an affinity chromatography extraction procedure Journal of Steroid Biochemistry 23 1043-1051

Wilmut I, Ritchie WA, Haley CS, Ashworth CJ and Aitken RP (1992) A comparison of rate and uniformity of embryo development in Meishan and Large White pigs Journal of Reproduction and Fertility 95 45-56 